METODOLÓGICOS E

NOVOS CENÁRIOS PARA

FUNDAMENTOS, ASPECTOS

\author{
SUSTENTABILIDADE

PARA

t

s.

(3) 


\section{SOBRE OS AUTORES}

\section{Guilherme Gasques Rodrigues | guigasques@gmail.com}

Lattes: http://lattes.cnpq.br/4719137365270751

Arquiteto e urbanista pelo Centro Universitário de Votuporanga (UNIFEV) e mestrando em arquitetura e urbanismo pela Universidade Estadual Paulista "Júlio de Mesquita Filho", Faculdade de Arquitetura, Artes e Comunicação (FAAC), Câmpus Bauru. Atua na linha "Teoria, História e Projeto", com o enfoque para metodologia de projetos arquitetônicos; sua pesquisa se concentra na arquiteta contemporânea Zaha Hadid.

Cláudio Silveira Amaral | cs.amaral@faac.unesp.br

Lattes: http://lattes.cnpq.br/2321257794011628

Pós-doutorado pela Fundação Casa de Rui Barbosa, bolsa FAPERJ (2014/2015); Pós-doutorado pela Ruskin Library and Research Centre da Universidade de Lancaster, bolsa FAPESP (2013); Doutor e Mestre pela FAU-USP (2005); Arquiteto e Urbanista pela FAU-PUCC (1979); Professor e Pesquisador sobre Metodologia de Projetos de Arquitetura no Curso de Pós-Graduação da Faculdade de Arquitetura, Artes e Comunicação da Unesp; Autor dos livros: John Ruskin e o Ensino do Desenho no Brasil pela Edt. Unesp; The influence of John Ruskin on the teaching of drawing in Brazil pela Editora EDWIN MELLEN; Escritório: o espaço da produção administrativa em São Paulo pela Editorada Cidade/Hedra. 


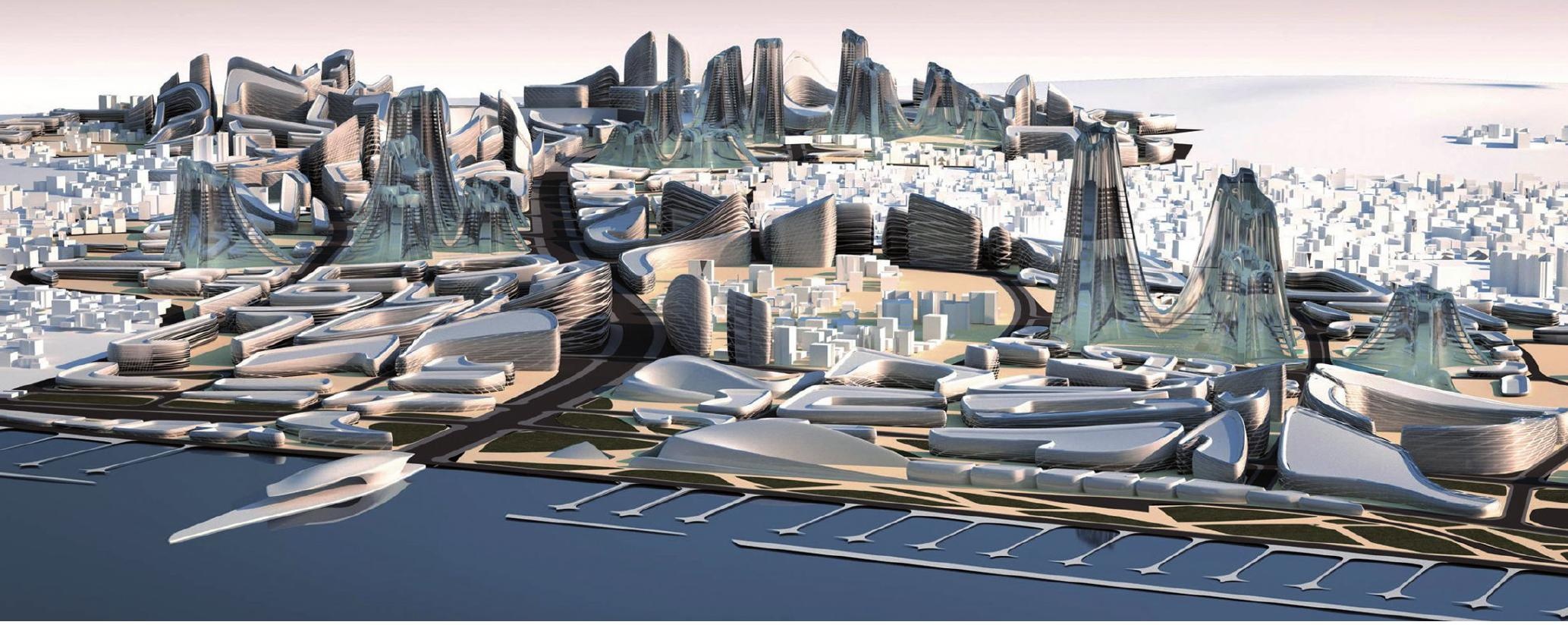

\title{
A metodologia de projeto de Zaha Hadid
}

\author{
Zaha Hadid's design methodology
}

Guilherme Gasques Rodrigues, Cláudio Silveira Amaral

\section{Resumo}

O objetivo deste artigo é caracterizar a metodologia de projeto da arquiteta Zaha Hadid. Os procedimentos metodológicos foram levantamentos bibliográficos, realizados em artigos, revistas, livros, documentários, entrevistas cedidas por Hadid e sócios. Conclui-se que o pintor moderno Kazimir Malevich foi uma influência seminal para a arquiteta. A paisagem natural, e seus elementos também serviram como inspiração para Hadid; os seus desenhos e pinturas foram muito utilizados para a elaboração de projetos no começo de sua carreira. Um novo estilo arquitetônico foi nomeado por Patrik Schumacher, o parametricism; estilo que reflete formas da paisagem natural.

Palavras-chave: Zaha Hadid; Kazimir Malevich; Metodologia de projeto; Parametricism.

\begin{abstract}
The objective of this article is to characterize the design methodology of the architect Zaha Hadid. The methodological procedures were bibliographic surveys made in articles, magazines, books, documentaries, interviews given by Hadid and partners. It is concluded that the modern painter Kazimir Malevich was a seminal influence for the architect. The natural landscape, and its elements also served as inspiration for Hadid; her drawings and paintings were widely used for the development of projects at the beginning of her career. A new style was named by Patrik Schumacher, the parametricism; stile which reflects natural landscapes forms.
\end{abstract}

Keywords: Zaha Hadid; Kazimir Malevich; Design methodology; Parametricism. 


\section{INTRODUÇÃO}

A problemática deste estudo refere-se a metodologia de projeto da arquiteta Zaha Hadid e seu escritório: Zaha Hadid Architects. Desde a sua formação pela Architectural Association, a AA, em Londres (GUCCIONE, 2011), Hadid construiu sua metodologia de projeto por meio de experimentações. $O$ pintor moderno Kazimir Malevich, precursor do suprematismo russo, foi uma inspiração para Hadid em experiências com desenhos e pinturas. A arquiteta elaborou seu projeto do quarto ano da faculdade sob esta influência, o projeto é nominado de Malevitch's Tektonik, 1976-7 (GUCCIONE, 2011). Tal inspiração também foi encontrada no primeiro projeto de concurso que Hadid venceu, o The Peak, Hong Kong (1982-1983). Em seu processo de criação foi possivel enxergar a metodologia de Hadid: diversos croquis, e pinturas com características semelhantes às de Malevich, além de conceitos projetuais sobre a manipulação do solo - a implantação do projeto no meio natural das montanhas (JODIDIO, 2013).

Hadid quando foi questionada como se inicia um projeto, respondeu que primeiramente realiza-se uma pesquisa para o uso do prédio, uma abordagem funcional. Após tal estudo, será realizado um diagrama que se desenvolverá no projeto. "O diagrama responde aos pedidos do cliente e ao terreno. Daí trabalhamos para elucidar o máximo possível para que se torne uma configuração legivel" (FIGUEROLA, 2012). Patrik Schumacher explicou melhor que este diagrama é um desenho que vem a ser mudado diversas vezes para ser compreendido como projeto, isto é chamado por ele de processo diagramático (LIMA; SCHRAMM, 2003). E, esta ferramenta foi encontrada nos projetos de Hadid, compondo sua metodologia; uma série de desenhos, pinturas, que resultavam em desenhos técnicos para a execução do projeto.

Por um longo período os desenhos e pinturas permaneceram fortemente em sua metodologia, porém com o avanço das tecnologias dos computadores, os projetos começaram a ser realizados mais rápidos e com muita precisão. 0 uso intenso dos computadores levou a criação de um novo estilo arquitetônico, o parametricim. Assim, denominado por Schumacher, sócio e agora diretor do Zaha Hadid Architects. Mas para Hadid a fase dos desenhos e pinturas foi muito importante, ela relatou que o processo de desenhar sobre o papel manteiga, adicionando 
camadas sobre outras, proporcionou a ela o que hoje é sua arquitetura, enfatizou que "ainda nos guiamos por esses princípios, mas os avanços na tecnologia nos permitem explorar em milhares de maneiras as camadas de desenhos e criar diferentes conceitos de maquetes ou esboços em 3D" (GARCIA, 2014, p. 19). Com a carência de estudos referentes a caracterização da metodologia de projeto de Hadid, este artigo faz-se presente com este objetivo. Identificando as inspirações e influências da arquiteta, que agora perduram em seu escritório.

Para atingir o objetivo, o estudo foi viabilizado por uma metodologia qualitativa, sendo bibliográfica, de caráter textual, iconográfico e audiovisual (documentário). Sendo assim, foi realizado um levantamento de fontes primárias e secundárias referentes: Zaha Hadid e a relação com as pinturas de Kazimir Malevich; o processo criativo referente aos desenhos, pinturas e programas de vanguarda; os projetos The Peak, Vitra Fire Station, Landscape Formation One e Hoenheim-Nord Terminus. Esta busca foi realizada em livros, artigos, revistas, documentários e entrevistas cedidas pela arquiteta e parceiros.

\section{ZAHA HADID E KAZIMIR MALEVICH}

Hadid nasceu em Bagdá em 1950, em 1971 se formou em matemática pela Universidade Americana de Beirute, no ano seguinte ingressou na Architectural Association, em Londres (GUCCIONE, 2011). Completou sua graduação em Arquitetura em 1977, e no ano seguinte ingressou no OMA, Office for Metropolitan Architecture, escritório de Rem Koolhaas e Elia Zenghelis, e com esta parceria começou a lecionar na $A A$. Nos primeiros anos de sua graduação Zenhelis foi seu professor, apresentando-a para Vanguarda Russa e consequentemente à Malevich (GMURZYNSKA et al. 2012). Em entrevista para a revista Florense, Hadid confirmou o interesse no trabalho do pintor respondendo que "Kasimir Malevich - uma grande influência para mim no que diz respeito à sua representatividade na vanguarda artística e na intersecção entre arte e design" (GARCIA, 2014, p. 17).

O movimento artístico denominado suprematismo por Malevich, foi definido como "identidade entre ideia e percepção, fenomenização do espaço num símbolo geométrico, abstração absoluta" (ARGAN, 2013, p. 324). Com uma ideologia revolucionária perante a sociedade, o artista 
Graças ao Suprematismo, abrem-se às artes plásticas novas possibilidades, na medida em que, abandonando as assim chamadas "considerações práticas", um sentimento plástico, reproduzido sobre a tela, pode ser transposto para o espaço. 0 artista (o pintor) não mais está preso à tela (à superfície do quadro) e pode transpor suas composições para o espaço. (MALEVICH, 1996, p. 350-351).

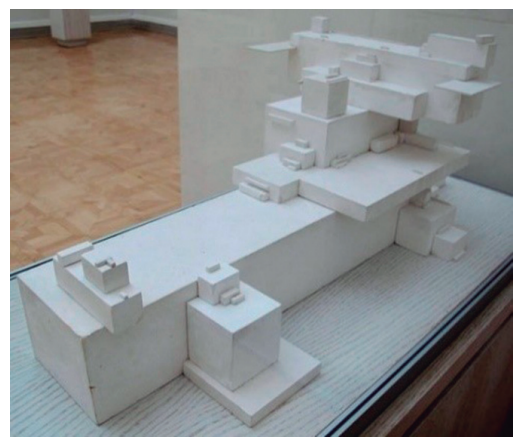

Figura 1: Kazimir Malevitch, alpha architecton, 1920. Fonte: Sailko, 2016.

1 Disponivel em: <https:/www. royalacademy.org.uk/article/zaha-hadidra-on-the-influence-of $>$. Acesso em nov. 2016.

2 "I was very fascinating by abstraction, and how... at really could lead to abstracting planes, moving away of kind... certainly dogmas about what architecture is... that project really liberated me, sent me free forms of all these rules" (BBC, 2014, transcrição nossa). utilizava seus quadros como ferramenta mental para expor estruturas e signos que simbolizavam a vida - o que ocorre no mundo interior e exterior de cada indivíduo (ARGAN, 2013).

O Quadrado Preto sobre o fundo branco (1915), uma obra suprematista marcante de Malevich, "foi a primeira forma de expressão do sentimento não objetivo: o quadrado sendo o sentimento e o fundo branco o "Nada" exterior a esse sentimento" (MALEVICH, 1996, p. 347). Argan, sobre as obras do pintor disse que "o quadro não é senão um meio para comunicar o estado não apenas de equilíbrio, mas também de identidade entre um sujeito e o objeto, (...) um instrumento mental, uma estrutura, um signo, que define a existência como equação absoluta entre o mundo interior e o exterior" (ARGAN, 2013, p. 324-325). Portanto, o Suprematismo é uma arte não objetiva, Malevich executava tais pinturas com o propósito de promover sensações, contrário de uma arte figurativa, que é compreendida de primeira instância. Malevich aplicou seu conceito de arte em também em formas tridimensionais, em maquetes de estudo espacial, denominadas architectons.

Hadid no final de sua graduação projetou o Malevitch's Tektonik (1976-7), um hotel na cidade de Londres, sobre o Rio Tâmisa. O projeto foi totalmente inspirado em uma obra específica de Malevich, chamada Architecton Alpha - uma escultura produzida pelo pintor, em uma fase que o mesmo começou a transpor suas pinturas em objetos tridimensionais. ${ }^{1}$ Nesse projeto, Hadid realizou uma pintura representando a locação do objeto em planos e inseriu tal imagem da escultura como conexão das margens do rio. 0 projeto tinha em seu programa quatorze níveis que aderiam à forma tectônica da escultura, e possíveis possibilidades de uso dos espaços foram gerados pelas restrições que a mesma concebeu (SCHUMACHER, Patrik et al. 2004, p. 11). Todo esse desenvolvimento fez a arquiteta desenvolver sua leitura pelo desenho abstrato, que posteriormente a forneceu uma capacidade de executar formas livres, pois ela havia se libertado de todas as regras de como projetar ${ }^{2}$.

Por meio do documentário "The Russian Revolutionary Zaha Hadid on Kazimir Malevich BBC Documentary"complementou-se o entendimento da inspiração de Hadid com Malevich. Foi relatado no documentário, que a arquiteta conseguiu enxergar as formas geométricas em diferentes escalas: como um globo, objetos voando à deriva, paredes ou móveis 
flutuando. ${ }^{4}$ Hadid interpretou os quadros de Malevich pelo seu ponto de vista; denotou-se que os mesmos transmitiram ideias criativas, e assim ela conseguiu enxergar o propósito desta arte - pinturas que provocam um pensamento.

A arquiteta possuía uma virtuosa leitura de desenhos abstratos, sabendo-se que a inspiração de Malevich foi essencial, visualiza-se que a conexão acontece por meio das pinturas e esculturas que ele concebeu. "Eu era fascinada por seu uso da abstração como princípio que impulsiona a criatividade a outros níveis de invenção" (GARCIA, 2014, p. 17). Seus primeiros trabalhos envolveram pinturas similares as de Malevich, sempre com o intuito da transposição para arquitetura.

Segundo Schumacher et al. (2004, p. 57), o movimento dos elementos que Hadid fazia nas pinturas, da perspectiva isométrica para uma projeção distorcida do espaço, resultava na ruptura da axonometria em fragmentos, uma experimentação audaciosa; mas foi neste processo de experimentação, que ela e seus companheiros de escritório puderam descobrir novas formas arquitetônicas. Desta maneira, de projeto em projeto, com a interpretação dos desenhos e pinturas a serem executados, resultou-se em obras construídas.

Hadid promoveu sua metodologia de projeto expondo a essência abstrata, manifestando contemporaneidade, "desde o início, sempre explorei o conceito de fragmentação, baseado na ideia de abstração e explosão, para desconstruir o que já vinha sendo exaustivamente repetido na produção em massa da arquitetura do século 20". (GARCIA, 2014, p. 17). A abstração anula o jeito de ler-fazer tipologias, não reconhece elementos comuns como janelas e portas, sendo assim Hadid recriou os limites dos planos e volumes (SCHUMACHER, 2004, p. 67).

\section{A INFLUÊNCIA DA PAISAGEM}

Com esta experimentação em pinturas, Hadid desenvolveu diversos projetos, Schumacher e Giusti demonstraram-nos no livro Zaha Hadid: projects documentation (2004), alguns exemplos são: Irish Prime Minister's Residence (1979-80), Berlim 2000 (1988), Office Building on Kurfurstendamm 70 (1986), Azabu-Jyuban Building (1987), A New Barcelona (1989), Tokyo International Forum (1989), entre outros. Um projeto que ganhou destaque,

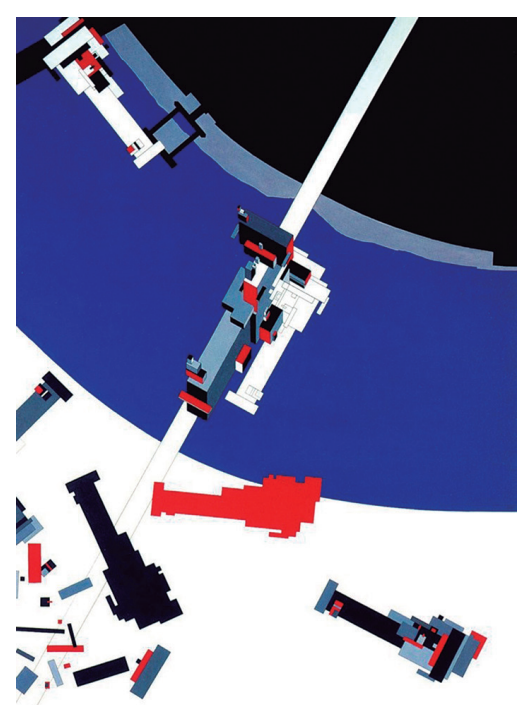

Figura 2: Malevitch's Tektonik, 1976-7. Fonte: Zaha Hadid Architects ${ }^{3}$

${ }^{3}$ Disponivel em: <http://www.zahahadid.com/architecture/malevichstektonik/>. Acesso em nov. 2016.

4 "But this could be seen many different scales, I mean could be, a scale of a very large globe, a scale of a kind moving spaceship, or moving object in space, moving object in space, or could be seen as a massive scale where they're lines or wall, or desk, or a chair" (BBC, 2014, transcrição nossa).

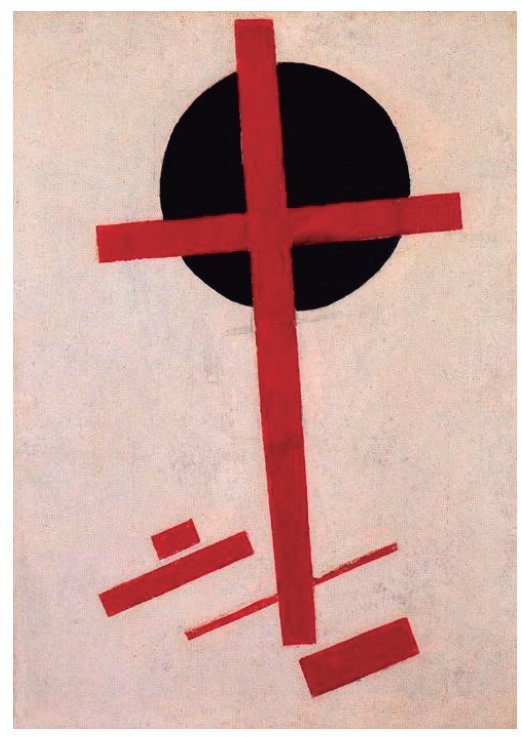

Figura 3: Suprematismo. Fonte: Tsavena, 2013 


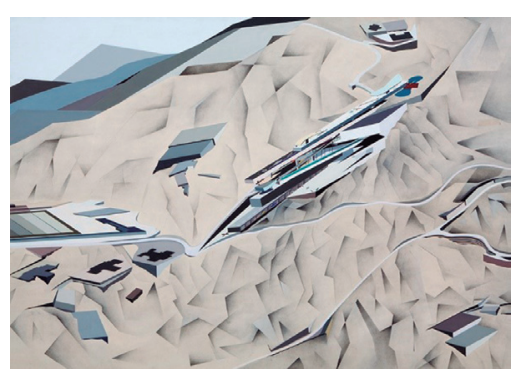

Figura 4: The Peak Club, 1982-3. Fonte: Dezeen, 2015.

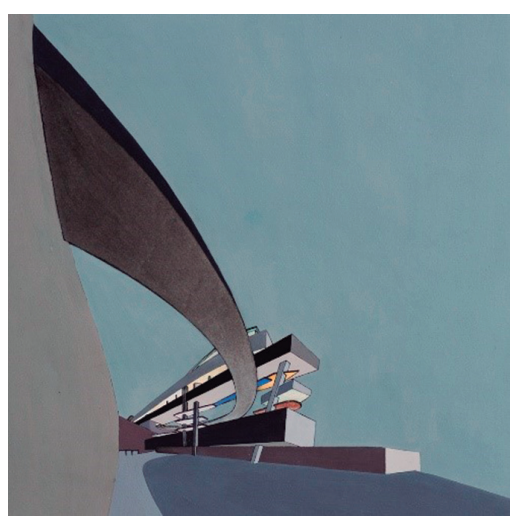

Figura 5: The Peak Club, 1982-3. Fonte: Dezeen, 2015.

\footnotetext{
${ }^{5}$ Original em inglês: (...) the architecture is like a knife cutting through the site. It cuts through traditional principles of organization and reconstitutes new ones, defies nature and resists destroying it.
}

foi o The Peak (1982-3), com ele Hadid venceu uma competição para projetar um clube de lazer, na cidade de Hong Kong. Este foi seu primeiro prêmio internacional, e foi um marco em sua carreira. 0 projeto posteriormente foi exposto no MoMA, na exposição Deconstructivist Architecture, em 1988 (JODIDIO, 2013). Hadid produziu diversas pinturas para a concepção do projeto, a Figura 4 demonstra o clube inserido no terreno, e na Figura 5 é possível notar quatro volumes que se sobrepõem, formando alguns vazios entre os mesmos. As pinturas foram denominadas pelo nome de "geologia suprematista", sendo possivel enxergar a referência de Malevich. A arquiteta produziu, além dessas pinturas, diversos croquis abstratos, que começavam a tomar forma nas telas; a arquiteta disse que sua "arquitetura é como uma faca cortando através do terreno, ela corta através dos princípios de organização tradicional e reconstitui novos, desafia a natureza e resiste a destruí-la"5 (JODIDIO, 2013, p. 53, tradução nossa).

Hadid demonstrou que seus desenhos e pinturas para este projeto eram um grande estudo de manipulação do solo (MOSTAFAVI, 2001). 0 solo foi modificado, reorganizado, os planos de lajes e as vigas, conformavamse em uma resolução geométrica distorcida (RUBY, 2006). 0 terreno do projeto localizava-se em uma região montanhosa de Hong Kong, para implantar o projeto o local seria escavado, as rochas retiradas

e posteriormente depois de polidas, retornariam ao local compondo uma paisagem artificial, mesclando/borrando com a paisagem natural (JOHNSON; WIGLEY, 1988). Jodidio (2013) disse que o "borrão", esta mescla das linhas projetuais do The Peak com a natureza (o penhasco), estão presentes nos trabalhos mais recentes de Hadid, e que este projeto foi considerado seminal na carreira da arquiteta. A arquiteta se referia ao projeto como uma "mudança sísmica suave", que de fato foi representada pelo seus desenhos e pinturas, que mudaram a visão do que a arquitetura poderia vir a ser, isto antes dos computadores avançados quebrarem de vez os conceitos do modernismo (JODIDIO, 2013).

Entende-se uma busca de mudança da forma arquitetônica, uma adaptação do projeto como uma paisagem. Hadid modificou na própria pintura sua visão do penhasco, do solo; deixando-o semelhante ao projeto. E a semelhança com a paisagem natural se configurou com o 
avanço das tecnologias dos computadores; essas máquinas com o passar do tempo ficaram mais potentes; e os programas foram capazes de representar a nível de execução formas mais ousadas.

Como foi visto no projeto The Peak, a topografia foi uma influência para o projeto, por meio de um solo irregular o clube foi configurado conforme a manipulação do mesmo. Em outros projetos Hadid elucidou a influência da paisagem natural como partido arquitetônico para conferir a forma do projeto. Um exemplo é o seu primeiro projeto construído, o Vitra Fire Station (1991-1993), localizado na cidade Weil Am Rhein, Alemanha. Este projeto também possuiu diversos desenhos e pinturas em seu processo de criação, a metodologia de Hadid continuou a mesma; o uso de ferramentas que possibilitaram uma experimentação com a plástica do projeto. Segundo Jodidio (2013), Hadid observou e projetou levando em conta o entorno da indústria Vitra. 0 edifício foi "previsto como uma zona de paisagem linear, quase como se fosse uma extensão artificial, referente aos padrões lineares dos campos de agricultura e vinicultura adjacentes"6 (JODIDIO, 2013, p. 119, tradução nossa).

Outro exemplo de projeto, é Landscape Formation One (1996-1999), localizado na mesma cidade que o Vitra Fire Station. O LF One, foi inspirado pelo entorno da paisagem natural, o projeto foi realizado para uma exposição de paisagismo, composto por um restaurante, salas para escritório e um ambiente de exibição (JODIDIO, 2013). Hadid disse que o projeto "vem de uma sequência de tentativas para extrair novas espacialidades fluídas, que derivam dos estudos sobre a formação da paisagem natural como os rios, montanhas, florestas, desertos, canyons, geleiras e oceanos"8 (JODIDIO, 2013, p. 133, tradução nossa).

Um terceiro exemplo é o projeto Hoenheim-Nord Terminus (1998-2001), na cidade de Strasbourg, França. Hadid projetou com bases de fluxos dos movimentos de carro, trens, bicicletas e pedestres um terminal de trem e ônibus, além de um estacionamento com capacidade para 700 veículos (JODIDIO, 2013). O projeto seguiu os experimentos realizados com Vitra Fire Station e o LF One, na ideia "da natureza artificial, que borra os limites dos ambientes naturais e artificiais"10 (JODIDIO, 2013, p. 151, tradução nossa).
${ }^{6}$ Original em inglês: (...) envisaged as a linear landscape zone, almost as if it were the artificial extension of the linear patterns of the adjacent agricultural fields and vineyards.

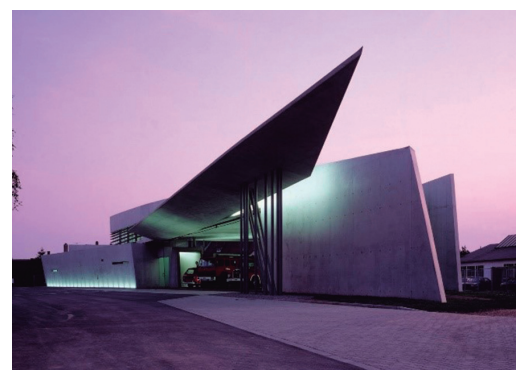

Figura 6: Vitra Fire Station, 1991-1993. Fonte: Zaha Hadid Architects7.

${ }^{7}$ Disponivel em <http://www.zahahadid.com/architecture/vitra-firestation-2/>. Acesso em nov. 2016

${ }^{8}$ Original em inglês: (...) is a part of a sequence of projects that try to elicit new fluid spatialities from the study of natural landscape formations such as river deltas, mountains ranges, forests, deserts, canyons, ice flows, and oceans.

Todas as minhas ideias vêm da observação: do lugar, da natureza, das pessoas se movendo pela cidade. É sempre sobre como as pessoas se movem por um espaço, e como o público vai usar o espaço. Ciência e natureza sempre foram inspirações frutuosas. Olhamos normalmente para os sistemas da natureza quando estamos trabalhando, observamos sua coerência e beleza (FIGUEROLA, 2012).

\footnotetext{
${ }^{10}$ Original em inglês: artificial nature (...) one that blurs the boundaries between naural and artificial environments.
} 


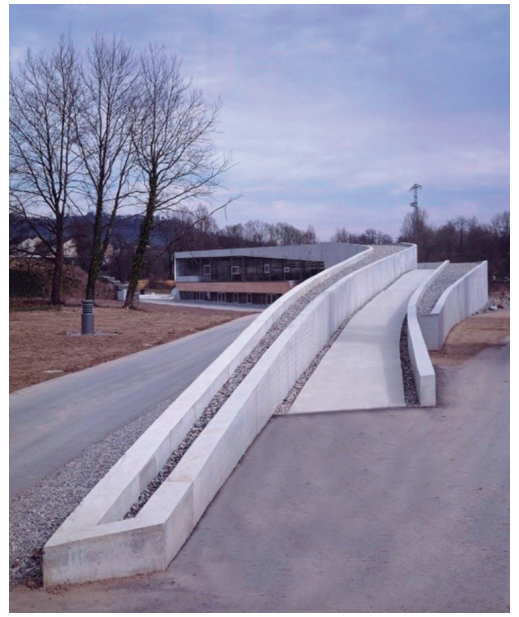

Figura 7: LF One, 1996-1999. Fonte: Zaha Hadid Architects ${ }^{9}$.

${ }^{9}$ Disponivel em <http://www. zaha-hadid.com/architecture/ landesgardenschau-landscapeformation-one/>. Acesso em no. 2016.

Pintar e desenhar marcaram o começo de minha carreira. 0 desenho permitiu a experimentação intensa da forma e do movimento, conduzindo à nossa abordagem radical de desenvolver uma nova linguagem para a arquitetura. As pinturas e croquis sempre serviram como ferramenta de análise e de pensamento: tenha seu tempo e desenhe (FIGUEROLA, 2012).

\footnotetext{
${ }^{11}$ Disponivel em <http://www.zahahadid.com/architecture/hoenheim-nordterminus-and-car-park/>. Acesso em no. 2016.
}

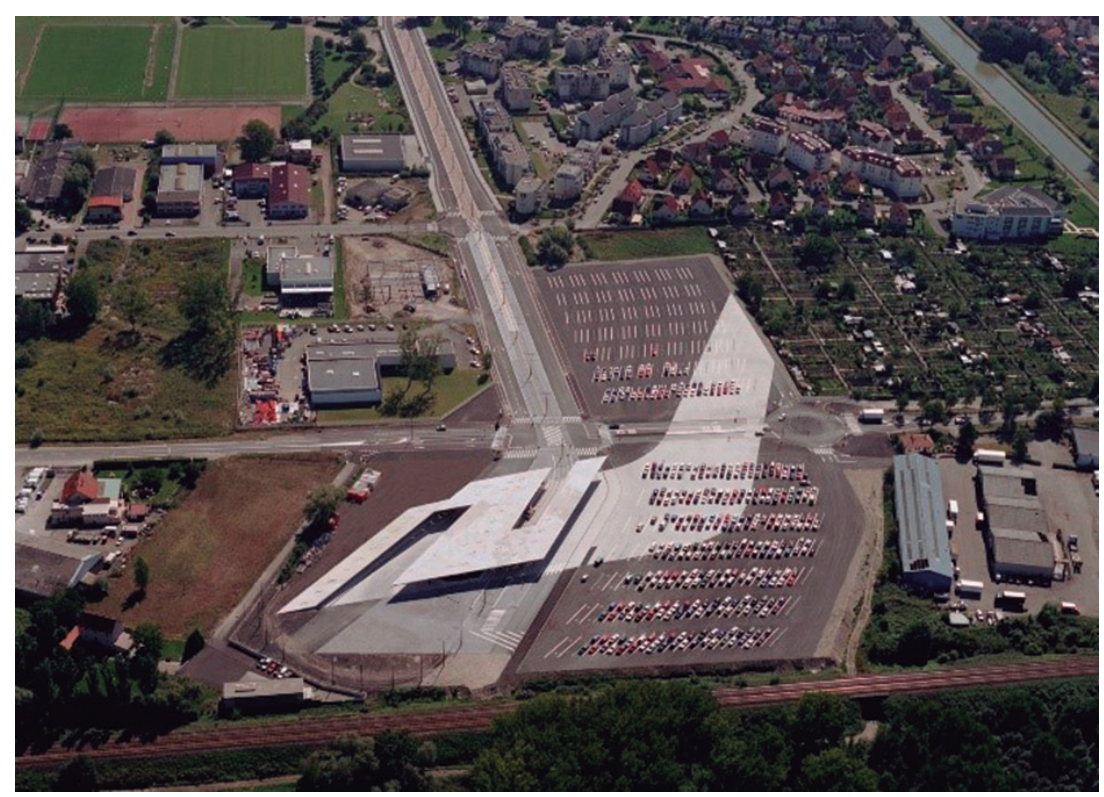

Figura 8: Hoenheim-Nord Terminus, 1998-2001. Fonte: Zaha Hadid Architects. ${ }^{11}$

\section{O ESTILO PARAMETRICISM}

Igualmente o The Peak, os últimos três projetos aqui citados possuíram desenhos e pinturas como ferramentas para a concepção projetual. A arquiteta explicou que "pintar, desenhar e esboçar foram ferramentas de suma importância na busca da minha expressão numa época em que softwares de desenho em 3D não existiam" (GARCIA, 2014, p. 18). Posteriormente por meio de alguns programas básicos para representar os desenhos, os projetos chegavam em uma resolução de execução - com o passar dos anos, eles foram aperfeiçoados. Em determinado momento os desenhos feitos a mão e pinturas deixam de ser usados na metodologia de Hadid, e os programas mais avançados assumem a posição para a criação, mas a arquiteta defende que:

Beatriz de Abreu e Lima (2003) levantou uma questão para Schumacher quando Hadid mencionou a grande pesquisa acerca dos desenhos, mostrando imagens de projetos já com o uso de programas em uma palestra. Assim, Lima perguntou sobre o uso do computador no escritório, e ele respondeu: 
Após a resposta, Lima (2003) deduziu que o computador chegou atrasado como ferramenta de projeto. Schumacher disse que "os trabalhos iniciais de Zaha, com suas pinturas, eram em grande parte analógicos e ainda era necessário projetar com maquetes ou plantas. As pinturas de Zaha permitiram ações mais liberais como, por exemplo, a distorção" (LIMA; SCHRAMM, 2003). Ainda explicou que atualmente, "é possível distorcer uma determinada figura, ou colidir duas figuras e depois alongá-las; algo que era desconhecido antigamente. Esta foi uma das audácias produtivas de Zaha" (LIMA; SCHRAMM, 2003). Sendo assim ficou claro que os desenhos e pinturas foram essenciais para a concepção de como Hadid e o escritório projeta; porém agora eles não são mais necessários, os computadores assumem a função do desenho, viabilizando a mesma experimentação que os desenhos e pinturas ofereciam.

Com a velocidade, precisão e avanço tecnológico dos programas computacionais, as formas arquitetônicas que já eram inspiradas pela paisagem, tornam-se mais maleáveis, sinuosas. Schumacher explicou esta influência da natureza, dizendo que Hadid fizera uma analogia da paisagem com as formas arquitetônicas. Extraindo de tal inspiração apenas questões de elementos como as curvas, inclinações, sinuosidades; e não uma tentativa de imitar a natureza, no sentido literal.

Na Bienal de Veneza de 2008 Schumacher publicou um manifesto definindo o estilo parametricism. 0 autor definiu o uso de programas como o Mel-script, Rhino-script'12, e também que o estilo deveria seguir determinadas regras como: evitar as formas geométricas comuns (quadrados, cubos, círculos, esferas, cilindros, cones e triângulos); evitar a repetição simples destes elementos e a justaposição sem relação dos mesmos; utilizar formas parametricamente maleáveis, com diferenças graduais (repetições) e que se relacionem sistematicamente. Schumacher ainda enfatizou que o estilo finalizou uma fase de transição, que foi composta pelos episódios do pós-modernismo, desconstrutivismo e minimalismo; e que estes estudos com animação digital foram realizados desde os anos de 1990 (SCHUMACHER, 2009).

Um projeto que exemplificou o fator das influências das linhas da natureza com o estilo parametricism é o Heydar Aliyev Cultural Center (2007-2013), localizado em Baku, Azerbaijão. 0 projeto abrange uma área de $52.417 \mathrm{~m}^{2}$, desde o edifício e sua área externa; o prédio comporta um
(...) é claro que usamos animações para visualizações internas e externas (walk-through, fly-through), porque tornam o fluxo espacial geral muito mais claro e pode-se então ter mais certeza do resultado e conhecer a fenomenologia resultante. Embora isso também pudesse ser feito antes por meio de desenhos à mão, havia sempre um pouco de incerteza sobre 0 fato de se estar inventando demais ou se o resultado seria realmente como o desenho. Os projetos nos quais eu trabalhei e que foram construidos, confirmaram de maneira surpreendente que é possivel antecipar os espaços por meio de desenhos $3 D$ feitos à mão. Só que hoje em dia, os computadores fazem a mesma coisa mais rápido e com mais precisão (LIMA; SCHRAMM, 2003).

Zaha introduziu a noção de paisagem artificial há muito tempo e eu acho que esta é uma analogia poderosa que introduz muitos elementos novos e poderosos ao repertório arquitetônico. Portanto, em primeiro lugar, é importante que usemos o termo Paisagem Artificial para que possa ser tratado como um tema abstrato. Não estamos falando sobre uma imitação visual da natureza. Estamos falando apenas sobre certos elementos de composição como inclinações e curvaturas no sistema. Também estamos falando de definições espaciais mais indeterminadas e abertas como, por exemplo, cumes, vales, uma floresta com graus de densidade; elementos que marcam e organizam, o espaço com, digamos, gradientes, com divisas indefinidas e formas latentes. (LIMA, SCHRAMM, 2003)

\footnotetext{
${ }^{12}$ Mel-script, Rhino-script são programas para modelagem em 3D, utiliza-se códigos para desenhar, e não o cursor do mouse como referência para comandos como nos programas mais usuais. Geralmente o Rhino é acompanhado do Grasshopper, plugin para executar a programação enquanto isto é feito em uma janela, o desenho é realizado em outra.
} 
${ }^{13}$ Original em inglês: fluid form which emerges by the folding of the landscape's natural topography and by the wrapping of individual functions of the Center.

${ }^{14}$ Disponivel em <http://www.zahahadid.com/architecture/heydar-aliyevcentre/>. Acesso em nov. 2016. grande hall, três auditórios, uma biblioteca e um museu (JODIDIO, 2013). Hadid disse que o design do projeto é "uma forma fluida que emerge pela dobra da topografia natural da paisagem e pelo enrolar das funções individuais do Centro"13 (JODIDIO, 2013, p. 357, tradução nossa).

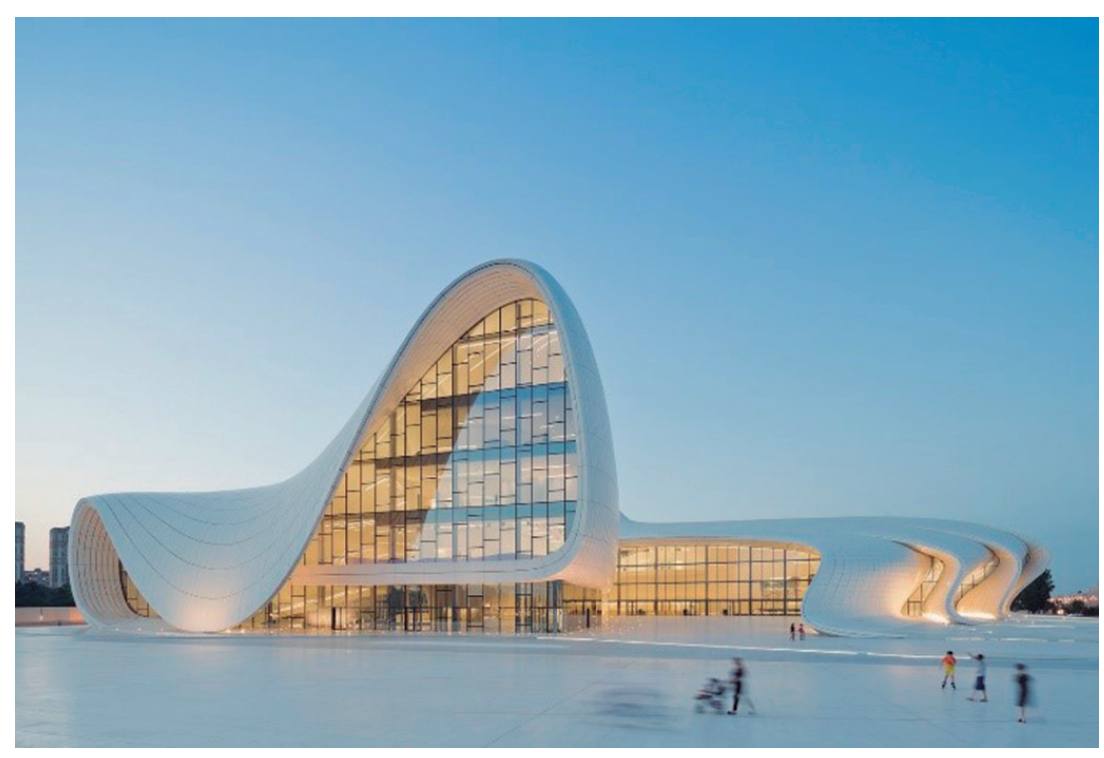

Figura 9: Heydar Aliyev Cultural Center, 2007-2013. Fonte: Zaha Hadid Architects. ${ }^{14}$

\section{CONSIDERAÇÕES FINAIS}

O pintor moderno Malevich foi de influência seminal na metodologia de projeto de Hadid. A arquiteta enxergou a inventividade suprematista e proporcionou isto a seus projetos, sendo possivel enxergar este conceito em seus desenhos e pinturas, que marcaram o começo de sua carreira. Estas ferramentas foram essenciais para a elaboração dos projetos mais atuais de seu escritório, pois apesar do âmbito artístico desaparecer por causa dos computadores, a liberdade de criação, e propulsão de experimentação resultou nas formas fluídas e de aspectos orgânicos. Juntamente com a inspiração provinda da natureza estabelece-se uma conexão com o parametricism, estilo que reflete formas da paisagem natural: curvas, sinuosidade e plasticidade orgânica. Classifica-se o estilo arquitetônico como paisagem artificial, por ser uma questão de projeto, realizada pelo homem, extraindo a essência da forma natural. 


\section{REFERÊNCIAS}

ARGAN, Giulio Carlo. Arte moderna: do iluminismo aos movimentos contemporâneos. 2. ed. São Paulo: Companhia das Letras, 2013.

BBC. Zaha Hadid on Kazimir Malevich. BBC CH/4. 2014. Disponivel em: <https:/www.youtube. com/watch?v=In9Hg_qlYZO>. Acesso em jul. 2016

DEZEEN. The Peak. Imagem do projeto. Disponivel em: <http:/www.dezeen.com/2016/07/13/ video-interview patrik-schumacher-meeting-zaha-hadid-the-peak-paintings-vitra-firestation-movie/>. Acesso em jul. 2016

FIGUEROLA, Valentina. Entrevista:Zaha Hadid fala sobre suas raízes e o processo de criação de suas obras. Revista AU, Edição 218, Maio de 2012. Disponível em: <http://au.pini.com. br/arquitetura-urbanismo/218/ela-materializa-o-fantastico-do-estigma-da-arquiteturado-258007-1.aspx>. Acesso em jul. 2016.

GARCIA, Cynthia. A arquitetura orgânica de Zaha Hadi. Revista Florense, Flores da Cunha, n. 41, p. 13-20, out, 2014

GMURZYNSKA, Krystyna; RASTORFER, Mathias; LEUNG, Melodie; SCHUMACHER, Patrik; OBRIST, Hans Ulrich; HEATHCOTE, Edwin; DOUGLAS, Charlotte; NAKOV, Andrei; LAVRENTIEV, Alexander; SCHACHTER, Kenny. Zaha Hadid and Suprematism. Galerie Gmurzynska, Zurich. Published by Hatje Cantz Verlag, 2012.

GUCCIONE, Margherita. Zaha Hadid. Tradução: Marcos Maffei. São Paulo: Folha de São Paulo, 2011

JODIDIO, Philip. Zaha Hadid: complete works 1979-today. Taschen, 2013

JOHNSON, Philip; WIGLEY, Mark. Deconstructivist Architecture. Museum of Modern Art/Little Brown and Company; 1st edition, 1988.

LIMA, Beatriz de Abreu; SCHRAMM, Mônica. Patrik Schumacher. Entrevista, São Paulo, ano 04, n. 013.01, Vitruvius, jan. 2003. Disponivel em: <http://www.vitruvius.com.br/revistas/read/ entrevista/04.013/3339> Acesso em set. 2016.

MALEVICH, Kazimir. Suprematismo. In: CHIPP, H. B. Teorias da Arte Moderna. São Paulo: Martins Fontes, 1996.p. 345-351.

MOSTAFAVI, Mohsen. Landscape as plan: a conversation with Zaha Hadid. Revista ElCroqui Zaha Hadid 1996-2001, n 103. 2001

RUBY, IIka; RUBY Andreas. Land\&ScapeSeries: Groundscapes, El reencuentro con el suelo en la arquitectura contemporánea, The rediscovery of ground in contemporary architecture. Barcelona: Editorial Gustavo Gili, SL, 2006

SAILKO. Kazimir malevich, alpha architecton, 1920. Disponível em: <https:/commons. wikimedia.org/w/index.php? search=Kazimir+alpha\&title=Special:Search\&go=Ir\&uselang= pt-br\&searchToken=6x92k3ahraOzOym6tvcycjy1 h\#\#/media/File:Kazimir_malevich,_alpha_ architecton,_1920_02.JPG >. Acesso em set. 2016.

SCHUMACHER, Patrik; GIUSTI, Gordana Fontana; COOK, Peter; LYNN, Greg; RUBY Andreas. Zaha Hadid: Texts and References. New York: Rizzoli International Publications, 2004.

SCHUMACHER. Parametricism as Style: Parametricism Manifesto. Presented and discussed at the Dark Side Club, 11 ${ }^{\text {th }}$ Architecture Biennale, Venice, 2008.

Parametricism: A New Global Style for Architecture and Urban Design. Architectural Design: Digital Cities, Vol. 79, n. 4, Julho/Agosto, 2009 
